\title{
O CONTEXTO DA ADOÇÃO DE CRIANÇAS QUE SÃO PÚBLICO-ALVO DA EDUCAÇÃO ESPECIAL E A RELAÇÃO FAMÍLIA-ESCOLA
}

\author{
Carolina Terribile Teixeira ${ }^{1}$, Elisane Maria Rampelotto ${ }^{2}$
}

\begin{abstract}
Resumo: O presente artigo aborda o tema da adoção de crianças público-alvo da Educação Especial, sinalizando o trabalho do(a) professor(a) de Educação Especial junto as famílias que optaram por adotar essas crianças. Para isso, uma pesquisa bibliográfica embasa este estudo que apresenta como referências: Venâncio (2005); Marconi, Presotto (2011); Weber (2011) dentre outros. O texto organizase, primeiramente, contextualizando, de maneira abrangente, a família; e em seguida sobre a adoção e, em específico, a adoção de crianças público-alvo da Educação Especial. Após, discorre sobre a relação escola, Educação Especial e família. Com a realização deste estudo, compreende-se a necessidade de incentivo a pesquisas que abordem o tema, devido à oportunidade de ampliação das discussões acadêmicas. Além disso, o assunto traz consigo a possibilidade de um olhar atento aos agentes influenciadores do abandono, da institucionalização e da adoção dessas crianças.
\end{abstract}

Palavras-chave: Educação Especial. Escola. Família. Adoção.

\section{ADOPTION CONTEXT OF CHILDREN WHO ARE TARGET AUDIENCE OF SPECIAL EDUCATION AND RELATION FAMILY-SCHOOL}

\begin{abstract}
This article approaches the theme of adoption of children who are target audience of Special Education, pointing out the Special Education teacher's work along with the families that chose to adopt these children. In order to do so, a bibliographical research bases this study that has as references: Venâncio (2005); Marconi, Presotto (2011); Weber (2011) among others. It is organized in such a way that initially approaches family, then adoption and specifically adoption of children who are target audience of Special Education. After, it discusses the relation among school, Special Education and family. By carrying out this study, we can understand the necessity of encouraging researches that approach this theme, because it allows the amplification of academic discussions, also that it is necessary to attentively look at the agents that influence abandonment, institutionalization and adoption of these children.
\end{abstract}

Keywords: Special Education. School. Family. Adoption.

1 Mestranda em Educação - Linha de Pesquisa Educação Especial na Universidade Federal de Santa Maria (UFSM). Especialista em Gestão Educacional (UFSM). Graduada em Educação Especial (UFSM). E-mail: carol_terribile@hotmail.com

2 Doutora em Educação. Professora Adjunta do Departamento de Educação Especial do Centro de Educação da Universidade Federal de Santa Maria. E-mail: elisane2007@gmail.com 


\section{Introdução}

O tema referente à adoção de crianças que são público-alvo da Educação Especial raramente é debatido, assim como, o trabalho do(a) professor(a) de Educação Especial junto as famílias que optaram por adotar essas crianças. A partir disso, surgiu a oportunidade e a vontade de estudar sobre a adoção de crianças público-alvo da Educação Especial, as relações sociais envolvidas e, junto a isso, fazer uma aproximação com a área de formação que é a Educação Especial.

Os caminhos percorridos pela adoção de crianças público-alvo da Educação Especial, Família e Escola (com destaque para a Educação Especial) estão entrelaçados ao longo deste texto. Para isso, o presente artigo apresenta ideias que partem de um estudo bibliográfico a respeito do tema que fomenta o embasamento para as discussões estabelecidas.

Para se discutir a respeito do contexto da adoção de crianças público-alvo da Educação Especial e da relação família-escola, precisa-se, primeiro, conhecer um pouco sobre família e o que permeia essa organização social. Isso porque a família é a responsável tanto por disponibilizar uma criança para adoção quanto para retirar essa criança do contexto. Dessa forma, inicialmente, serão abordadas questões sobre a família. Posteriormente, aprofundar-se-á, especificamente, ao assunto sobre a adoção de crianças que são público-alvo da Educação Especial. Em sequência, discorre sobre a relação escola, Educação Especial e família.

O texto organiza-se, primeiramente, contextualizando, de maneira abrangente, a família; e em seguida sobre a adoção e, em específico, a adoção de crianças público-alvo da Educação Especial. Após, discorre a texto, primeiramente, contextualizando, de maneira abrangente, a família; e em seguida sobre a adoção e, em específico, a adoção de crianças público-alvo da Educação Especial. Após, discorre sobre a relação escola, Educação Especial e família.

\section{Família e o viver em sociedade}

A família é uma forma de agrupamento humano que está presente em diversas sociedades. É classificada, originalmente, como um fenômeno biológico, mas, com o passar do tempo, tornou-se um fenômeno social (MARCONI; PRESOTTO, 2011). As famílias variam em estrutura e organização, geralmente são formadas por laços religiosos e/ou contratuais, como por exemplo, o casamento.

Dessa forma, as famílias são permeadas por questões particulares de seus integrantes como interesses, sentimentos que fomentam essa relação que é estabelecida dentro desse fenômeno social. A partir da constituição dessas relações e interações no meio social e no âmbito familiar que se efetivam diferentes comportamentos que podem estar de acordo ou não com as normas da sociedade. Dentre essas circunstâncias surgem tanto os atos de abandono, como os atos de adoção de crianças, influenciados por interesses 
e situações diversas. Nos casos de abandono a maior evidencia está relacionada a falta de recursos financeiros para o sustento da criança, já nos casos de adoção salienta-se o desejo de ter um filho(a) e não poder gerá-lo(a). Sendo assim, posteriormente, essas questões serão discutidas de forma mais ampla.

A sociedade é organizada por regras que são estabelecidas e devem ser cumpridas por todos. Desse modo, é preciso seguir com rigorosidade as leis sociais, e aqueles que, por ventura, acabam quebrando regras e cometendo erros tentam de diversas formas escondê-los. O abandono de crianças é, historicamente, uma das situações que está relacionada a esses casos.

O abandono, a vida em lares substitutos e a adoção fazem parte da história da infância. Segundo Venâncio (2005, p. 30-31),

\begin{abstract}
Um dos feitos dessa história social da infância foi o de descobrir que o abandono de crianças, sobretudo de recém-nascidos, tem raízes antigas. $\mathrm{Na}$ Europa, tal prática foi abundantemente registrada na literatura clássica. No final da Idade Média, principalmente após a Peste Negra (1348), o problema se agravou. O número de bebês pobres e órfãos se multiplicou, exigindo uma intervenção das instituições dos burgos e cidades medievais. Em Portugal, antes mesmo da colonização do Brasil, câmaras municipais e hospitais, como as Santas Casas da Misericórdia, começaram a criar formas de auxílio destinadas às crianças abandonadas.
\end{abstract}

Essas práticas assistencialistas foram se tornando presentes na sociedade, pois os "filhos do abandono" precisavam ser amparados. O abandono de crianças, além de ser influenciado por regras sociais sobre as ações da família, também era um reflexo de questões econômicas.

O fator econômico levava ao abandono não só nos casos de órfãos, como também de filhos vivos. Para uma família estruturada, mas de poucos recursos, o nascimento de uma criança com problemas físicos ou mentais significava perigo à sobrevivência econômica (Id, 2004, p. 44).

Além disso, destaca-se também a afirmação de Silva (2012, p. 15) que diz que "a infância pobre demorou a adquirir direitos e as práticas de institucionalização foram criadas para essa parcela da população". O abandono geralmente ocorria ou por parte de famílias pobres, ou por serem crianças filhas de mães solteiras, ou filhos fora do casamento. Um fato interessante é que raramente as escravas abandonavam os filhos, já que eles também eram propriedade de seu Senhor (VENÂNCIO, 2004, 2005).

Atualmente, no Brasil, a institucionalização como forma de acolhimento de crianças e de adolescentes tem caráter temporário. Entretanto, referente a isso, Siqueira e Dell'Aglio (2010, p. 413) destacam que, 
Apesar de o abrigamento ser uma medida de proteção excepcional e temporária, é possível observar que muitas crianças e adolescentes permanecem por muitos anos institucionalizados, embora mantenham contato com a família.

Sobre isso, Teixeira (2014) comenta que, no caso de crianças com deficiência que vivem em instituições de acolhimento, o tempo de permanência acaba sendo maior devido essas crianças não terem o perfil desejado para adoção. Ao fazer esse breve panorama a respeito de características familiares, do abandono e da institucionalização de crianças, percebe-se como o processo foi percorrido historicamente. Após essa apresentação, o tema é ilustrado de melhor forma, possibilitando que se compreenda a importância em ser debatido e trazido à tona no campo educacional.

$\mathrm{Na}$ área da Educação, principalmente na Educação Especial, faltam estudos que visualizem as crianças em situação de institucionalização como forma de acolhimento e adoção. Logo, é inegável a significação de vislumbrar essas realidades que influenciam no ambiente escolar e no processo de ensino e de aprendizagem.

No caso de crianças público-alvo da Educação Especial, quando se encontram em situação de acolhimento institucional, é muito difícil que encontrem famílias interessadas em adotá-las (WEBER, 2011). A partir dessa concepção, começa-se a entender o processo de adoção no Brasil e como ele está se modificando ao longo dos tempos.

\section{A adoção no Brasil}

$\mathrm{O}$ ato de adoção passou por muitas transformações ao longo dos séculos. Acompanhou, com o passar do tempo, as modificações na estrutura da sociedade. No início do século XX, era comum que as crianças fossem acolhidas por famílias como filhos de criação, já que ainda não se tinha uma legislação vigente que tratasse da situação dessas crianças. Elas, muitas vezes, eram responsáveis pelo serviço doméstico (SILVA, 2012) ou auxiliavam nele, como forma de retribuir à família por seu acolhimento e pela oportunidade de estar integrada a ela, tendo casa e comida. Outros, que eram minoria, eram realmente tratados como filhos por suas respectivas famílias.

Ao fazer leituras e demais pesquisas, observou-se que a adoção teve muitas facetas, entre elas duas que se destacam: a adoção por casais estéreis que, geralmente, já estavam em idade madura; e a outra como ato assistencial (SILVA, 2012). É possível perceber diferenças nas intenções das duas, pois enquanto a primeira serve para suprir o desejo de constituir uma família de casal e filho(s), a segunda serve como um auxílio, proteção, para aqueles que são de famílias numerosas. Ou seja, faz-se a caridade de criar determinada criança para que ela tenha a oportunidade de crescer em um convívio familiar, melhor estruturado do qual ela é originária. Fica caracterizada aqui a função social estabelecida pelo ato da adoção, que tem representatividade histórica no nosso país. 
[...] a adoção só vai adquirir um sentido mais social e vincular-se à preocupação com a orfandade e o abandono de crianças após a Primeira Guerra Mundial, que gerou um grande contingente de crianças sem pais. É desse momento em diante que se inverte a lógica da adoção, a qual passa a ser entendida como uma solução para o bem-estar de crianças cujos pais estão ausentes (WEBER apud SILVA, p. 33, 2012).

Ao analisar o caminho percorrido pela adoção e a função social que exerce, percebe-se que ainda, no Brasil de hoje, há motivações semelhantes às do passado que levam ao ato de adoção. Porém, o processo em si sofreu alterações que o tornaram mais organizado e preza pelos direitos e deveres do adotado e do adotante. Com o passar do tempo, surgiram várias definições e conceitos para a adoção que foram se refinando, conforme as adaptações da sociedade. Porém, é preciso ter cuidado e cautela para definir e conceituar essa atitude que implica tantas pessoas e contextos diferentes. Deve-se considerar que a adoção, além de acontecer via trâmite jurídico, envolve sentimentos, desejos, sendo, portanto, bastante subjetiva.

Como exemplo, cita-se o conceito apresentado por Gonçalves (2010, p. 362) que diz "adoção é ato jurídico solene pelo qual alguém recebe em sua família, na qualidade de filho, pessoa a ela estranha". Com base nisso, reflete-se sobre as relações estabelecidas pela adoção, pois as relações familiares e sociais são fatores fundamentais para a constituição desse sujeito e o reflexo de suas atitudes na sociedade. Conforme o autor apresenta, a criança adotada é uma pessoa estranha que passa a ser integrada à família, mas se não há amor e respeito entre as partes envolvidas, esse processo tratado como ato jurídico "friamente" pode levar a situações psicológicas e comportamentais que prejudiquem o bom desenvolvimento e amadurecimento dessa criança.

Portanto, a pessoa quando toma a decisão de realizar a adoção de criança ou de adolescente deve procurar o Juizado da Infância e Juventude e submeter-se ao protocolo; após isso, irá fazer parte do cadastro. Ele informará suas preferências em relação ao adotado como: idade, cor de pele e sexo (SOUZA; CASANOVA, 2011). Uma questão importante em relação ao processo de adoção e que acarreta problemas, tornando o processo mais longo, é que a maioria das crianças, em instituições de acolhimento disponíveis para adoção, não se enquadram no perfil requerido pelos candidatos adotantes. Então, passam muito tempo nas instituições ou, até mesmo, nunca chegam a ser adotadas.

A adoção é rodeada por medos e mitos e, por isso, é importante que a pessoa que pretende realizar o ato de adoção esteja consciente da decisão que tomou e muito bem resolvida para não ficar com dúvidas e medos. A autora Weber (2011) apresenta treze mitos sobre a adoção, são eles:

- Filhos adotivos sempre têm problemas;

- Crianças disponíveis para adoção sempre têm histórias horríveis; 
- Filhos que foram adotados sempre pensam na família de origem e querem conhecê-la;

- Escolher a criança a ser adotada facilita o vínculo afetivo;

- Pessoas mais esclarecidas são menos exigentes e têm menor preconceito;

- Adotar deve ser natural e não é preciso ter preparação especial;

- A motivação para a adoção é sempre a infertilidade;

- A motivação perfeita para a adoção é fundamental para o sucesso de adoção;

- Somente pessoas com alto poder aquisitivo podem adotar;

- É melhor a criança não saber de sua adoção;

- É melhor não falar muito do assunto com o filho adotivo para não potencializar a importância da família de origem;

- Filhos que foram adotados sempre terão traumas; e

- Atualmente ninguém mais discrimina famílias que adotam crianças.

Os medos das pessoas ao que se refere à adoção, em sua maioria, são gerados pelos mitos, preconceitos e pelo desconhecimento sobre a temática. É necessário e interessante que as pessoas que pretendem realizar a adoção ou que simplesmente querem saber mais sobre o assunto procurem pessoas que trabalhem, direta ou indiretamente, com a adoção, frequentem os grupos de apoio ou simplesmente leiam sobre o assunto a partir de fontes confiáveis. Dessa forma, terão acesso ao conhecimento no que diz respeito à adoção e poderão desvencilhar-se dos medos, mitos e preconceitos.

A existência de vinte tipos de adoção é destacada por Souza e Casanova (2011), são elas: adoção por casal; adoção por solteiro; adoção clandestina ou ilegal; adoção precoce; adoção tardia; adoção de grupos de irmãos; adoção de indígena; adoção inter-racial; adoção direta; adoção unilateral; adoção de embriões; adoção póstuma; adoção mista; adoção por homoafetivos; adoção irregular; adoção anônima; adoção internacional; brasileiros que desejam adotar crianças estrangeiras; adoção de adultos; adoção de criança especial. A existência de tantos tipos de adoção não é muito divulgada, as quais são desconhecidas do público em geral; dentre as citadas, algumas são polêmicas e/ou não estão bem resolvidas. Inclui-se nisso a adoção de criança especial que é desconhecida por muitos e cercada de medos e mitos.

É importante ser ressaltado aqui que, antes da decisão de adotar, é preciso que se reflita muito a respeito do que se pretende e das condições existentes para isso. A criança ou adolescente não são brinquedos que, quando perdem a graça, devolve-se ou abandona-se; adoção é um ato de responsabilidade. Diante disso, a seguir, inicia-se a abordar mais em específico a adoção de crianças público-alvo da Educação Especial e, assim, passa-se a destacar fatores importantes a respeito da adoção dessas crianças 
e da família adotante. Dessa forma, abordar-se-á questões relevantes que permeiam o processo de adoção.

\section{Adoção de crianças público-alvo da Educação Especial e Família Adotante}

A adoção de crianças público-alvo da Educação Especial segue os mesmos procedimentos estabelecidos pela Lei Nacional de Adoção no 12.010 de 3 de agosto de 2009. Em seu artigo 28, parágrafo 5o, está exposto que há uma preparação e acompanhamento realizados por uma equipe interprofissional antes de a criança ser inserida em uma família substituta. Na mesma lei, o artigo 87 prevê campanhas de estímulo ao acolhimento através da obtenção de guarda e cita diferentes características das crianças dentre as quais estão as com necessidades específicas de saúde ou com deficiências.

O Estatuto da Pessoa com Deficiência de 2006 (Brasil, 2006) define direitos fundamentais às pessoas com deficiência como, por exemplo, o que diz respeito à saúde, à vida familiar, à assistência social, à educação e à acessibilidade. No documento, também consta o que se entende por pessoa com deficiência, como aquela que tem restrição mental, física ou sensorial dentro de uma das seguintes categorias: deficiência física, deficiência auditiva, deficiência visual, deficiência mental, surdocegueira, autismo, condutas típicas, lesão cerebral traumática, deficiência múltipla. Crianças ou adolescentes com esses casos geralmente, permanecem em uma instituição sem perspectivas de fazer parte de um meio familiar.

A maioria das crianças com algum tipo de deficiência, que são entregues em instituições como Casas de Apoio, são deixadas lá por seus próprios pais. Esses fazem isso por medo, preconceito ou por não ter condições de arcar com os cuidados necessários para com esse(a) filho(a).

\footnotetext{
Outro aspecto que deve ser levado em consideração é a realidade das famílias que abandonam particularmente as crianças com necessidades especiais. Geralmente, trata-se de pais e de mães que carregam consigo sua própria história de carência e abandono, o que, juntamente com a insegurança em relação ao futuro dessas crianças, leva-os a deixarem seus filhos nas instituições que abrigam menores (FONSÊCA; SANTOS \& DIAS, 2009, p. 303).
}

Essas crianças passam a ser um motivo de preocupação não só para a instituição que a acolheu, mas para o Estado que deve garantir seu direito como cidadão de crescer em uma família e ter acesso a políticas sociais públicas que possibilitem seu desenvolvimento. Acontece que o Estado não faz um programa de conscientização dos possíveis pais adotantes em relação a essas crianças e nem oferece um auxílio financeiro ou educacional. Isso porque a família que estiver disponível e interessada em adotar uma criança com deficiência precisará de recursos com tratamentos e acompanhamentos profissionais, tanto no campo da saúde como no educacional. 
Os pais que procuram a adoção esperam que, por meio dela, tenham o seu sonhado filho(a) perfeito(a) e repelem, geralmente, qualquer alternativa que vislumbre o contrário.

\begin{abstract}
Desenvolver motivação para adoções especiais, crianças [...], com necessidades especiais: [...]. Ao ouvir casos sobre adoção e compreender que crianças têm prioridade e é um direito da criança de viver em família, é possível desenvolver também em alguns adotantes um lado altruísta que as leve a adotar crianças diferentes do perfil idealizado (WEBER, 2011, p. 37).
\end{abstract}

Alguns se sensibilizam e resolvem apostar em uma adoção de crianças públicoalvo da Educação Especial, mas é de suma importância que estejam conscientes da responsabilidade que estão assumindo e que também estejam livres de preconceitos. Logo, adoção não é caridade. As pessoas, quando ainda têm dúvidas sobre a adoção de crianças público-alvo da Educação Especial, procuram auxílio de profissionais, como, por exemplo, médicos, a fim de terem maiores informações a respeito dos aspectos clínicos apresentados pela criança que pretendem adotar. A ideia de adoção dessas crianças pode não ser bem recebida pelo profissional procurado e pela família extensa de quem pretende realizar essa ação. Com isso, os possíveis adotantes podem acabar se decepcionando, mas é importantíssimo que busquem outros profissionais para sanarem todas as suas dúvidas e, assim, tomarem uma decisão consciente no momento da adoção.

A opção pela adoção de crianças público-alvo da Educação Especial impõe a necessidade de preparação das pessoas dispostas a realizá-la, para enfrentar situações de preconceito, intolerância e também de admiração. Isso porque esse ato pode despertar, nas pessoas, os mais diversos sentimentos, por ser uma atitude considerada contrária ao que a maioria da sociedade espera.

Mas o que a sociedade espera? A sociedade espera que aquelas pessoas que desejam filhos e decidem optar pela adoção acolham em suas famílias crianças saudáveis e bonitas, capazes de se adequarem e viverem no mundo capitalista ao qual se faz parte. Sendo assim, o pensamento preconceituoso leva em consideração apenas o fato de que uma criança com deficiência pode vir a se tornar um sujeito sem autonomia e incapaz de competir, produzir e consumir. É preciso ampliar a visão, deixar de ver apenas aquilo que não será capaz de fazer e sim enxergar as possibilidades daquilo que poderá vir a fazer e aprender.

Por outro lado, o ato da adoção de crianças público-alvo da Educação Especial pode gerar admiração por parte de outras pessoas. Pode ser compreendido como um ato de coragem, desprendimento e amor. Com isso, as pessoas envolvidas só têm a ganhar, quem adota por viver uma experiência ímpar, e quem é adotado por ter a oportunidade de fazer parte de uma família, ser respeitado e amado.

A família precisa estar preparada para atender às necessidades dessa criança, que podem incluir desde hospitalizações, tratamento psicológico e outros diversos atendimentos na área da saúde e/ou educação. Até mesmo, em alguns casos, 
peculiaridades, como distúrbio alimentar, do sono ou afetivo. No entanto, se a família não está bem organizada e planejada, pode passar a sofrer certos dilemas, como diz Campos (2009, p. 29):

[...], os pais de crianças com deficiência passam pelo dilema de conciliar trabalho, obrigação pessoal e cuidado maternal. Dilemas que ocasionados pelas necessidades, [...], através do cuidado com a casa, da orientação para a vida, das expectativas sobre o futuro, da dignidade do sustento e dos cuidados com a família.

Sendo assim, é preciso que os pais adotantes de crianças público-alvo da Educação Especial estejam disponíveis a enfrentar o desafio, acompanhem todo o processo de adaptação da criança na família e procurem profissionais que os auxiliem a compreendêla da melhor forma possível. Conseguinte, torna-se imprescindível o debate acerca da relação que se estabelece ou que precisa ser estabelecida entre a escola, a educação especial e a família adotante da criança público-alvo da Educação Especial envolvida. A discussão a esse respeito será discorrida ao longo do próximo item que também se propõe a fazer um fechamento reflexivo sobre o tema abordado.

\title{
Relação Escola, Educação Especial e Família
}

\begin{abstract}
Com o aburguesamento da família, a criança aparece como centro das atenções emocionais dos pais e como pedra angular dos projetos para o futuro. Considerada na época pré-moderna como simplesmente um adulto incompetente, a criança torna-se, segundo a nova concepção, um ser em formação que carece de especiais cuidados materiais e afetivos. Surge então um exército de especialistas para melhor definir as necessidades da criança e para aconselhar os pais sobre como criá-la. No lugar da antiga sociabilidade da rua e da ajuda mútua do clã, a família conjugal e seu complemento, a escola, se consolidariam com o propósito de satisfazer todas as necessidades afetivas e pedagógicas da criança (FONSECA, 1995, p. 125).
\end{abstract}

As crianças público-alvo da Educação Especial, por muito tempo, foram segregadas, tanto da convivência familiar como da escola. Elas eram motivo de medo e de vergonha. Com o tempo, essa concepção foi sendo mudada e entendida, passando por diversos caminhos até chegar ao que se segue hoje. Inicialmente, surgiram as escolas especiais; mais tarde, as classes especiais e, atualmente, o movimento da inclusão (MENDES, 2010). Para que essa inclusão de fato aconteça, faz-se necessário que os professores em geral busquem conhecimentos para que ao se depararem com essa situação saibam lidar com ela da melhor forma possível, contribuindo para a inclusão escolar e social dessas crianças (CARVALHO, 2014).

Ressalta-se o que diz Souza e Casanova (2011, p.148): "não há motivo de ter 'compaixão' porque a criança foi adotada, nem tampouco protegê-la”. Dessa forma, quando for realizado algum trabalho que fale sobre família, pode ser abordada a questão da adoção, sempre com cuidado para não expor de forma desnecessária nenhum aluno. 
[...] não se trata de "integrar crianças com deficiência", mas sim de permitir ou conquistar, junto à escola, o acesso e o convívio com a diferença e, em um sentido mais amplo, conceder aos alijados do ensino regular o pleno acesso a ele. Através da inclusão, não são apenas as crianças que são acolhidas na escola regular, mas também os pais podem igualmente ser acolhidos à medida que participam de eventos na escola: reunião de pais, conselhos de pais e mestres, comemorações etc. Isso pode conceder a eles não apenas visibilidade, mas participação e inserção sociais (CAMPOS, 2009, p. 57).

A relação família-escola e família-professor de Educação Especial são muito importantes e refletem no comportamento e na aprendizagem da criança. Assim como, a relação entre a gestão da escola e o professor de Educação Especial, pois o profissional precisa do apoio dos demais colegas que dividem o espaço escolar para realizar o seu trabalho da forma mais adequada possível.

Os dois espaços - o familiar e o escolar- são fundamentais para o desenvolvimento infantil e um precisa apoiar e colaborar com o outro para juntos traçar um objetivo em comum e alcançá-lo. Esse objetivo deve primar pelas melhores condições de cunho afetivo e educacional para a criança, evitando práticas preconceituosas e segregadoras.

Segundo Sigolo e Oliveira (2008, p. 165), "embora essas relações sejam de natureza complexa, [...], não há como negar que a criança no seu desenvolvimento partilha das influências destes dois contextos durante parte significativa da sua vida". Por isso, a comunicação é a melhor forma de construir uma relação sólida entre escola e família, possibilitando, assim, o melhor entendimento e atendimento da criança.

\section{Conclusão}

Ao realizar o estudo proposto, percebeu-se o quanto este é um campo vasto e pouco explorado na produção de pesquisa acadêmica. Após o estudo bibliográfico, tevese a possibilidade de ampliação de conhecimentos a respeito dos fatores envolvidos nos atos de abandono, na institucionalização e na adoção de crianças, assim como, sobre a família e o seu conviver em sociedade. A partir disso, pode-se compreender, de melhor forma, o tema abordado.

Fica explícito que o contexto social no qual a família está inserida, mesmo que os mais diversos, influencia na decisão de abandono e de institucionalização das crianças público-alvo da Educação Especial. Dessa forma, entende-se que valores, normas ditados por padróes sociais, assim como, a falta de recursos para atender a necessidade dessas crianças pode afligi-las, influenciadas por meio do preconceito e da negligência.

Por isso, pesquisar sobre as questões que envolvem a adoção de crianças que são público-alvo da Educação Especial é um campo bastante rico, porém, com poucos estudos. É necessário que sejam incentivadas pesquisas nesse viés, as quais possibilitam 
abordar, de forma mais abrangente, assuntos diferenciados dentro dos estudos em Educação Especial.

\section{Referências}

BRASIL. Constituição (1988). Constituição da República Federativa do Brasil de 1988. Disponível em: <http://www.planalto.gov.br/ccivil_03/Constituicao/Constituicao.htm>. Acesso em: 18 mar. 2016.

BRASIL. Lei 8.069 (1990). Estatuto da Criança e do Adolescente no Brasil. Disponível em: <http://www.planalto.gov.br/ccivil_03/LEIS/L8069.htm>Acesso em: 18 mar. 2016.

BRASIL. Estatuto (2006). Estatuto da Pessoa com Deficiência. Disponível em: <http:// www.camara.gov.br/sileg/integras/432201.pdf>. Acesso em: 18 mar. 2016.

BRASIL. Lei 12010 (2009). Lei da Adoção. Disponível em: <http://www.planalto.gov.br/ ccivil_03/_Ato2007-2010/2009/Lei/L12010.htm>Acesso em: 18 mar. 2016.

CAMPOS, Crispim A. Esperanças equilibristas: a inclusão de pais de filhos com deficiência. Curitiba: Juruá, 2009.

CARVALHO, Rosita E. Educação inclusiva: com is pingos nos “is". Porto Alegre: Editora Mediação, 2014.

CENTRO UNIVERSITÁRIO UNIVATES. Manual da UNIVATES para trabalhos acadêmicos. Disponível em:< http://www.univates.br/editora-univates/media/ publicacoes/110/pdf_110.pdf>. Acesso em: 19 nov. 2016.

FONSÊCA, Célia M. S. M. S.; SANTOS, Carina P.; \& DIAS, Cristina M. S. B. Adoção de crianças com necessidades especiais. Disponível em: < http://www.scielo.br/pdf/paideia/ v19n44/a03v19n44.pdf>. Acesso em: 5 nov. 2012.

FONSECA, Claudia. Caminhos da adoção. São Paulo: Cortez, 1995.

GONÇALVES, Carlos. R. Direito civil brasileiro. 5 ed. São Paulo, SP: Saraiva, 2010.

MARCONI, Marina de A.; PRESOTTO, Zélia M. N. Antropologia: uma introdução. São Paulo: Atlas, 2011.

MENDES, Enicéia G. Breve Histórico da educação especial no Brasil. Revista Educación y Pedagogía, vol. 22, n.57, may./ago, 2010. Disponível em: <http://aprendeenlinea.udea.edu.co/ revistas/index.php/revistaeyp/article/view/9842/9041>. Acesso em: 20 nov. 2016.

RAMPELOTTO, Elisane M. Mesmidade ouvinte \& Alteridade Surda: invenções do outro surdo no Curso de Educação Especial da Universidade Federal de Santa Maria. 2004. Tese (Doutorado em Educação) - Universidade Federal do Rio Grande do Sul, Porto Alegre, ago. 2004.

SIGOLO, Silvia R. R. L.; OLIVEIRA, Adriana M. L. A.. Relação Família-Escola e o Processo de Inclusão Escolar - Subsídios para Orientação Familiar. In: MENDES, Eniceia. 
G.; ALMEIDA, Maria A; HAYASHI, Maria C. P. I. (Orgs.). Temas em educação especial: conhecimentos para fundamentar a prática. Brasília, DF: CAPES - PROESP, 2008.

SILVA, Milena L. Lei Nacional de adoção e acolhimento institucional: o ponto de vista de psicólogos e assistentes sociais. 2012. Dissertação (Mestrado em Psicologia) - Universidade Federal de Santa Maria, Santa Maria, 26 jan. 2012.

SIQUEIRA, Aline C.; DELL'AGLIO, Débora D. Crianças e Adolescentes

Institucionalizados: Desempenho Escolar, Satisfação de Vida e Rede de Apoio Social.

Psicologia: Teoria e Pesquisa, jul./set 2010, vol. 26 n. 3, p. 407-415. Disponível em: <http:// www.scielo.br/pdf/ptp/v26n3/a03v26n3.pdf>. Acesso em: 2 dez. 2013.

SOUZA, Hália P. de. CASANOVA, Renata P. de S. Adoção: o amor faz o mundo girar mais rápido. Curitiba: Juruá, 2011.

TEIXEIRA, Carolina T. Gestão Educacional e Inclusão: visualizando alunos com deficiência em situação de acolhimento institucional. 2014. Monografia (Especialização em Gestão Educacional) - Universidade Federal de Santa Maria, Santa Maria, 30 jul. 2014.

VENÂNCIO, Renato P. Mensagens do abandono. In: Revista de História da Biblioteca Nacional. Rio de Janeiro, RJ, ano 1, no 4, 2005.

VENÂNCIO, Renato P. Entregues à própria sorte. In: Nossa História. Rio de Janeiro, RJ, ano 1, no 9, 2004.

WEBER, Lídia N. D. Adote com carinho: um manual sobre aspectos essenciais da adoção. Curitiba: Juruá, 2011. 